\title{
Hypertension management in rural western Kenya: a needs-based health workforce estimation model
}

\author{
Rajesh Vedanthan ${ }^{1^{*}}$ (D), Danielle J. Lee ${ }^{2}$, Jemima H. Kamano ${ }^{3}$, Omarys I. Herasme ${ }^{4}$, Peninah Kiptoo ${ }^{5}$, \\ Deborah Tulienge ${ }^{5}$, Sylvester Kimaiyo ${ }^{3,5}$, Hari Balasubramanian ${ }^{6}$ and Valentin Fuster ${ }^{7}$
}

\begin{abstract}
Background: Elevated blood pressure is the leading risk for mortality in the world. Task redistribution has been shown to be efficacious for hypertension management in low- and middle-income countries. However, the workforce requirements for such a task redistribution strategy are largely unknown. Therefore, we developed a needs-based workforce estimation model for hypertension management in western Kenya, using need and capacity as inputs.

Methods: Key informant interviews, focus group discussions, a Delphi exercise, and time-motion studies were conducted among administrative leadership, clinicians, patients, community leaders, and experts in hypertension management. These results were triangulated to generate the best estimates for the inputs into the health workforce model. The local hypertension clinical protocol was used to derive a schedule of encounters with different levels of clinician and health facility staff. A Microsoft Excel-based spreadsheet was developed to enter the inputs and generate the full-time equivalent workforce requirement estimates over 3 years.

Results: Two different scenarios were modeled: (1) "ramp-up" (increasing growth of patients each year) and (2) "steady state" (constant rate of patient enrollment each month). The ramp-up scenario estimated cumulative enrollment of 7000 patients by year 3, and an average clinical encounter time of 8.9 min, yielding nurse full-time equivalent requirements of $4.8,13.5$, and 30.2 in years 1, 2, and 3, respectively. In contrast, the steady-state scenario assumed a constant monthly enrollment of 100 patients and yielded nurse full-time equivalent requirements of 5.8, 10.5, and 14.3 over the same time period.

Conclusions: A needs-based workforce estimation model yielded health worker full-time equivalent estimates required for hypertension management in western Kenya. The model is able to provide workforce projections that are useful for program planning, human resource allocation, and policy formulation. This approach can serve as a benchmark for chronic disease management programs in low-resource settings worldwide.
\end{abstract}

Keywords: Hypertension, Low- and middle-income countries, Workforce estimation, Task redistribution

\section{Background}

The global burden of hypertension predominates in lowand middle-income countries (LMICs), with $80 \%$ of hypertension-related deaths occurring in those regions [1]. However, treatment and control rates in these regions are poor [2, 3], due to inequitable access to health care, failure to uptitrate anti-hypertensive therapy, co-morbidities (e.g.,

\footnotetext{
* Correspondence: rajesh.vedanthan@nyulangone.org

${ }^{1}$ New York University School of Medicine, 180 Madison Avenue, 8th Floor,

New York, NY 10016, USA

Full list of author information is available at the end of the article
}

obesity and diabetes), insufficient lifestyle modification, poor medication adherence, and psychosocial factors [4-9].

In addition to these barriers, LMICs also have insufficient human resources for health [10]. Given the severe shortage of physicians in LMICs, task redistribution of hypertension care from physicians to non-physician health workers could improve hypertension treatment and control rates in low-resource settings worldwide [11, 12]. However, the workforce requirements for such a task redistribution strategy are largely unknown.

(c) The Author(s). 2019 Open Access This article is distributed under the terms of the Creative Commons Attribution 4.0 International License (http://creativecommons.org/licenses/by/4.0/), which permits unrestricted use, distribution, and reproduction in any medium, provided you give appropriate credit to the original author(s) and the source, provide a link to the Creative Commons license, and indicate if changes were made. The Creative Commons Public Domain Dedication waiver (http://creativecommons.org/publicdomain/zero/1.0/) applies to the data made available in this article, unless otherwise stated. 
In this paper, we describe the development of a needsbased workforce estimation model for hypertension management in Kenya, modeled after a similar workforce estimation model developed for human immunodeficiency virus (HIV) care in Mozambique [13]. We aimed to estimate the number of physicians, nurses, clinical officers, and auxiliary personnel necessary to provide stable, long-term care for patients with hypertension in this resource-limited setting.

\section{Methods}

\section{Aim}

To develop a needs-based workforce estimation model for hypertension management in western Kenya, using need and capacity as inputs.

\section{Setting}

Since its initiation in Kenya in 2001, the Academic Model Providing Access to Healthcare Partnership (AMPATH) has established an HIV care system that has served over 160,000 patients [14]. Recently, in collaboration with the government of Kenya, AMPATH has broadened its clinical scope of work to include hypertension care $[15,16]$. Our research study was conducted within the AMPATH catchment area in the Kosirai and Turbo divisions of western Kenya. Each division has one rural health center and several more decentralized rural dispensaries.

\section{Conceptual model}

We developed a needs-based workforce estimation model that took into account need and capacity, resulting in fulltime equivalent health workers. The definition and formula for each of these are as follows:

1. Need: If $i$ denotes patient category and $j$ denotes type of provider, then need is the total number of clinical encounters per month for provider $j\left(v_{j}\right)$ required to care for all hypertension patients in category $i\left(n_{i j}\right)$, depending on the different encounter frequency $\left(f_{i j}\right)$ that patient category $i$ needs with provider type $j$.

$$
v_{j}=\Sigma_{i}\left(f_{i j} \times n_{i j}\right)
$$

2. Capacity is the number of patient encounters possible per month $\left(E_{j}\right)$ for a provider, depending on the amount of patient-contact time $\left(t_{j}\right)$ each type of provider can work per month and the average productivity of each type of provider (time per clinical encounter $\left.\left(m_{j}\right)\right)$.

$$
\text { Capacity : } E_{j}=t_{j} / m_{j}
$$

3. The final output is full-time equivalents (FTEs) $\left(F_{j}\right)$ required for a type of provider to meet the total need:

$$
F_{j}=v_{j} / E_{j}
$$

\section{Data collection}

A combination of key informant interviews, focus group discussions, a Delphi exercise, and time-motion studies were utilized to generate the data required to calculate the inputs into the health workforce model (Fig. 1). Results from each of these techniques were triangulated to generate the best estimates for inputs into the model.

Key informant interviews: Key informant interviews (KIIs) were conducted with AMPATH's Chronic Disease Management (CDM) leadership, patients, and community leaders $(N=7)$. The interviews took place at a private location convenient for the interviewees. Prior to initiating the KIIs, verbal informed consent was obtained from each study participant. All interviews were audiorecorded verbatim, with the research staff member taking notes.

Focus group discussions: Focus group discussions (FGDs) were conducted with health workers and patients $(N=6)$. The FGDs were scheduled at a location that was mutually convenient for all participants. Verbal informed consent was obtained from each FGD study participant. All group discussions were audio-recorded verbatim, and the moderator took notes during the discussions.

Both the semi-structured KIIs and the FGDs aimed at exploring the participants' assessments of the type and number of personnel that would be required for a nurse management of hypertension program at that point in time, as well as projected into the next several years. The audio-recordings from all of the sessions were transcribed and translated into English by an interpreter. Content analysis of the transcribed interviews, discussions, and moderator notes was performed by first assigning unique codes based on content [17], according to the following deductive (a priori) codes: (1) estimated and anticipated number of hypertension patients to be managed, (2) estimated and anticipated number of nurses required to provide hypertension care; (3) types and number of other personnel required for hypertension management, and (4) workflow 


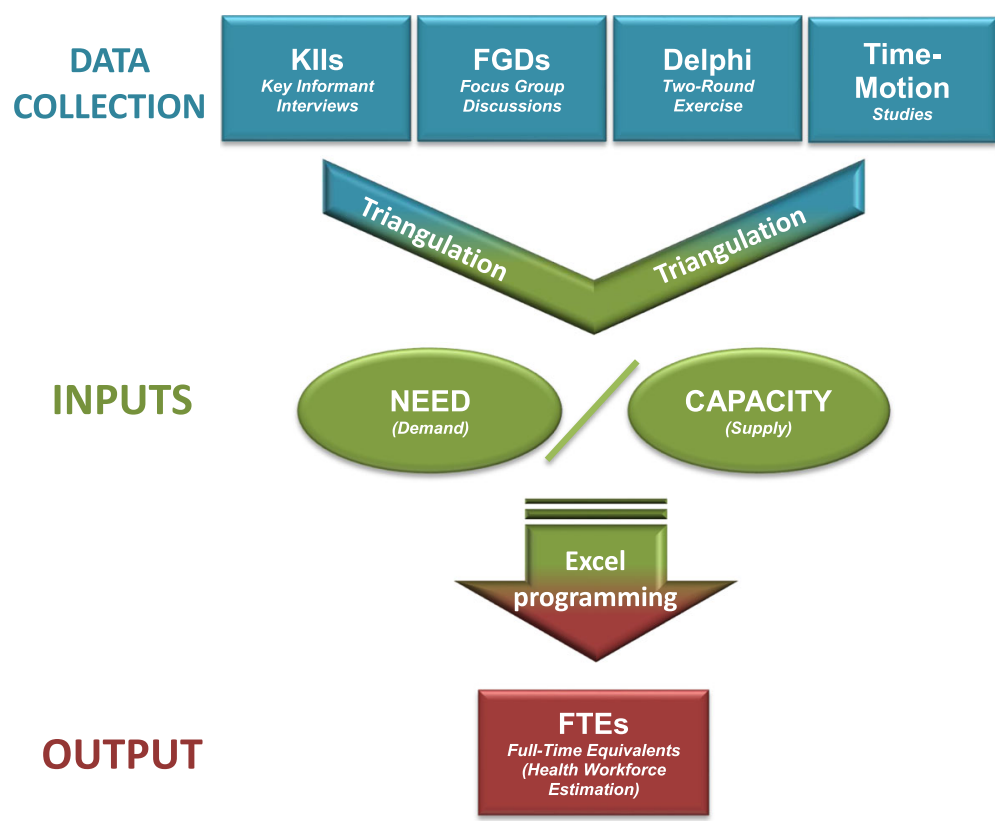

Fig. 1 Overall approach to the study, illustrating the data collection elements, triangulation to create the model inputs, and generation of the model output using the Microsoft Excel-based worksheet.

and work-time allocation. Significant inductive (emerging) codes were also identified. Codes were subsequently grouped together by theme, and the relationships between and among them were formulated.

Delphi exercise: We conducted a two-round Delphi exercise involving eight invited experts in hypertension management, health care in Kenya, or behavioral research. The Delphi exercise is a consensus-building, group facilitation technique that collects expert opinions through several rounds of surveys or interviews and is characterized by anonymity, iteration, controlled feedback, and statistical group response (expression of the degree of consensus within a group) $[18,19]$. Exemption from informed consent among this study group was requested and approved due to the minimal risk and absence of any personal health information involved with this technique.

In the first round, each participant was asked to estimate the number and complexity of hypertension patients in western Kenya, health workforce requirements to manage hypertension, and expected 1-year outcome for such patients. In the second round, each participant has presented the first-round responses of all other participants in an anonymous fashion and again asked to answer the same questions. At the conclusion of the second round, the estimates for each of the items were summarized using descriptive statistics (mean and range).

Time-motion studies: Time-motion studies were conducted in order to supplement information relating to capacity. Patients seen at rural dispensaries within the AMPATH catchment area of Kosirai and Turbo were eligible to participate in this component of the study. After written informed consent was obtained from each participant, a research staff member timed the duration of a clinical encounter between each patient and the rural clinician. The research team member did not enter the examination room during the health worker's interaction with the patient, but rather observed and took notes from outside the room at the start and end of the clinical encounter. The Time-Motion Study application by Graphite, Inc. (Sacramento, CA), was used to record the time of each clinical encounter. One-hundred-and-eighteen clinical encounters were observed over seven days in seven rural dispensaries-66 patients with hypertension and 52 patients without hypertension. Each patient's demographic and clinical information was also extracted from the clinical record in an anonymous fashion. The results were summarized using descriptive statistics.

\section{Model development}

The AMPATH clinical protocol for hypertension management being used at the time of the model development and data collection (2013-2014) was derived from the evidence-based standards of the Seventh and Eight Reports of the Joint National Committee (JNC) on Prevention, Detection, Evaluation, and Treatment of High Blood Pressure (JNC 7 and JNC 8) [20, 21] using drugs contained in the Kenyan national formulary [22] and has been shown to reduce blood pressure among patients with hypertension [23]. This clinical protocol (Appendix) was used to determine "patient states" (e.g., systolic 
blood pressure (SBP) $\geq 140 \mathrm{mmHg}$ and $<180 \mathrm{mmHg}$ ), each of which was linked to a specific management plan (e.g., "educate on lifestyle changes and repeat blood pressure in one month"). This yielded 26 unique "patient categories," each of which combined a patient state with a management plan (Fig. 2). We defined three possible outcomes for each patient category: improvement (BP controlled), no clinical change, and worsening. Each of these outcomes would then determine the subsequent patient state (e.g., SBP remains $\geq 140 \mathrm{mmHg}$ and $<180$ $\mathrm{mmHg}$ upon repeat measurement) and linked management plan (e.g., "enroll into nurse-managed care and initiate pharmacotherapy"), corresponding to the subsequent patient category.

The 26 patient categories were collapsed into six "clinician-frequency combinations." More clinically complex patients are seen by higher-level providers, with higher frequency. In the example above, a patient enrolled in nurse-managed care who has initiated pharmacotherapy would be seen by a nurse every month (Fig. 3a); in contrast, a patient with diabetes and hypertension (reflecting greater clinical complexity) would be seen by a clinical officer every month. For every clinician-frequency combination, we created a schedule of "encounters" (which clinician or staff person a patient sees during each patient "trip" to the health facility). In the example above, for the patient enrolled in nurse-managed care, the patient would encounter the nurse, the pharmacist (for medication refill), and the triage staff (for intake and registration) at every trip. At the end of a 6-month period, the patient category and clinician-frequency combination would be reassessed, allowing for patients to either improve, remain in the same state, or worsen, with a corresponding change in category and clinician-frequency combination (Fig. 3b). We created a model for 3 years, with 6-month reassessments based on usual clinical practice according to the AMPATH clinical protocol.

Similar to the workforce estimation model developed for HIV care in Mozambique [13], our model was programmed using spreadsheet technology in Microsoft Excel 2010 (Redmond, WA). Variables that can be modified include both demand (need) and supply (capacity) variables and include the following:

1. Demand (need):

(a) Distribution of patients across patient categories and clinician-frequency combinations (i.e., what proportion of patients need to be seen by a nurse vs. a physician; what proportion of patients need to be seen every 1 month vs. every 6 months).

(b) Total number of patients, either as target/ expectation at the end of each year, or number enrolling per month.

(c) Patient attrition due to loss to follow-up.

2. Supply (capacity):

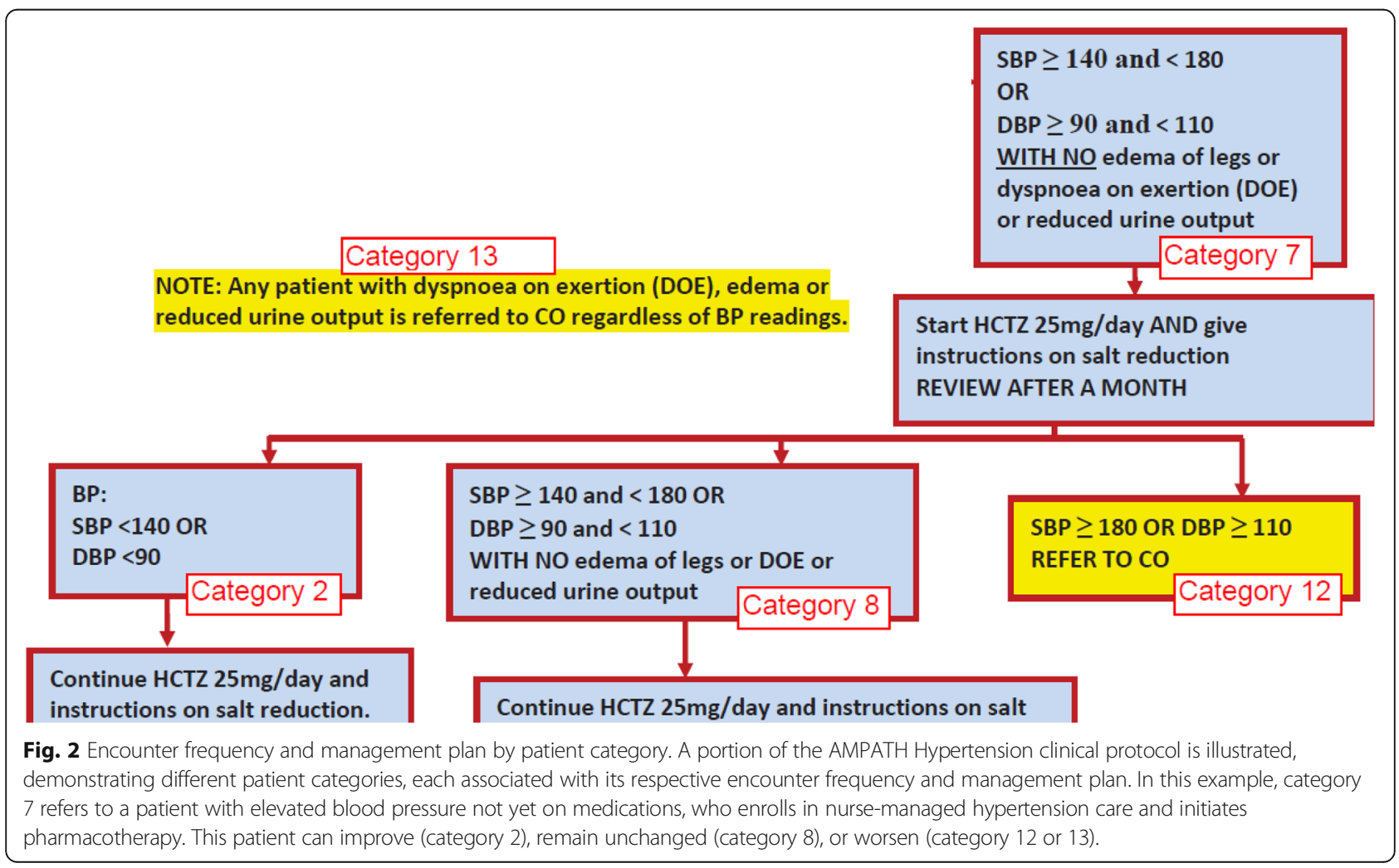




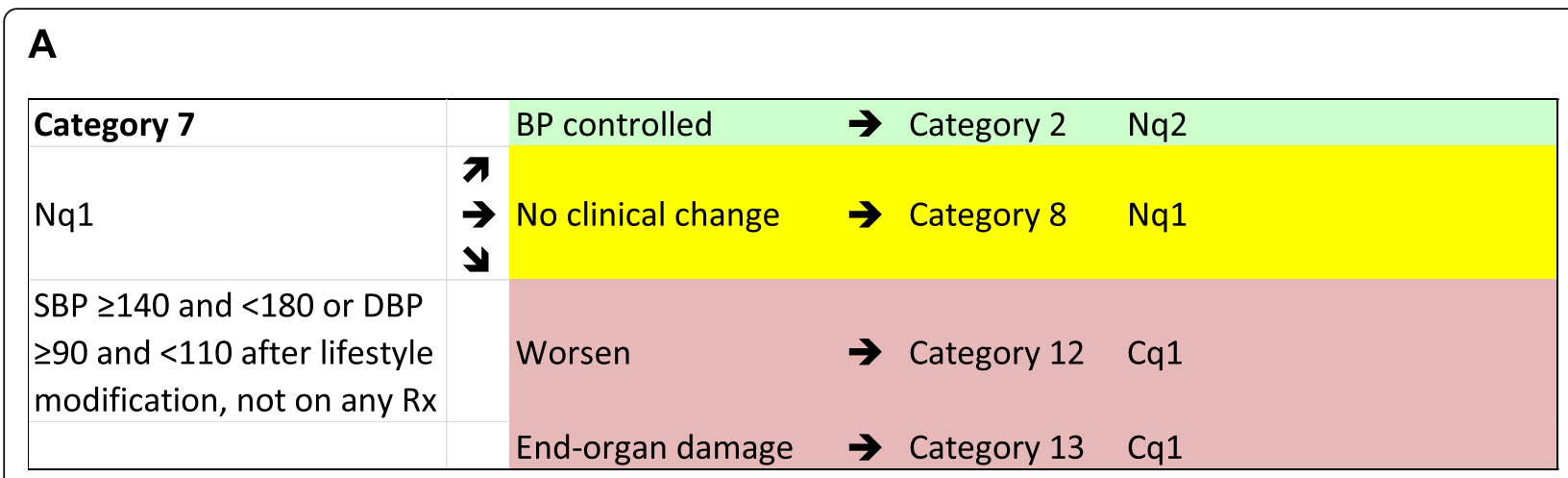

B

\begin{tabular}{|c|c|c|c|c|c|c|c|c|}
\hline & & & & & & & & Possible Outcomes \\
\hline Nq1 & Enrollment month & 1 & 2 & 3 & 4 & 5 & 6 & Improve --> Nq2 \\
\hline \multirow[t]{6}{*}{ Nurse, q1 month } & HTN Rx month & 1 & & & & & & No Change --> Nq1 \\
\hline & Physician & & & & & & & Worsen --> Cq1 \\
\hline & Clinical Officer & & & & & & & \\
\hline & Nurse & $x$ & $x$ & $x$ & $\mathrm{x}$ & $x$ & $\mathrm{x}$ & \\
\hline & Pharmacist & $x$ & $x$ & $x$ & $x$ & $x$ & $x$ & \\
\hline & Triage Staff/Technician & $x$ & $x$ & $x$ & $x$ & $x$ & $x$ & \\
\hline
\end{tabular}

Fig. 3 Change in frequency of required nurse visits (a) and schedule of encounters with providers (b) for an individual patient. a A patient being seen by a nurse every month ( $\mathrm{Nq} 1$ ) can either improve and transition to being seen every 2 months (Nq2), remain unchanged and continue to be seen every month ( $\mathrm{Nq} 1$ ) or worsen and require referral to a higher level of care (clinical officer) to be seen every month (Cq1). b The schedule of encounters for each patient, demonstrating that the $\mathrm{Nq}^{1}$ patient sees the nurse, pharmacist, and triage staff during each monthly trip to the health facility.

(a) Number of encounters per day per FTE for each type of provider (e.g., nurses can see more patients than physicians due to lowercomplexity patients requiring less time per encounter).

(b) Total number of days available for clinical encounters.

Three worksheets are required to generate the estimate of need/demand. Worksheet A has rows that correspond to every clinician-frequency combination linked to every potential outcome after 6 months. The columns correspond to each month in the 3-year period (36 months). Each cell corresponds to the number of encounters that a patient has with each type of provider at that particular time point.

Worksheet B has a similar structure to worksheet A with rows corresponding to every clinician-frequency combination linked to 6-month outcome, as well as 36 columns. However, each cell corresponds to the total number of encounters per type of provider, taking into account the inputs with respect to the total number of patients per month.

Worksheet $\mathrm{C}$ is from the health system perspective and also has 36 columns for the 3-year period. The number of rows consists of the number of provider types multiplied by 36 (number of months in the model).

A fourth worksheet, worksheet D, takes inputs for both need and capacity and generates the FTE requirement for each year, according to Eq. (c) above. The model allows for two different scenarios. One scenario allows the user to enter the total number of patients enrolled at the end of each year-this scenario allows for flexibility to ramp up enrollment in subsequent years after starting with relatively slower enrollment. A second scenario allows the user to enter the number of new patients enrolled per month-this scenario mimics more of a "steady state" of new patients being enrolled at a relatively constant rate when the clinical program is more established.

\section{Results}

Results from the Delphi surveys indicated that as of 2014, an estimated range of 3000-5000 patients was being treated by an estimated range of 10-70 nurses. By the end of 2015, there was a projected increase of 20006000 more patients, with an additional 10-80 nurses required to treat the greater need.

Results from the time-motion studies identified that among the hypertensive patients, approximately $60 \%$ 
required follow-up in 1 month, $32 \%$ in 2 months, and $8 \%$ in 6 months. Results from our time-motion studies and FGDs estimated that for nurses, the available patient contact time was 720 min per month (assuming 2 days per month dedicated to seeing hypertension patients in clinic, and $6 \mathrm{~h}$ per clinical day available to see patients), with the time per clinical encounter equaling $8.9 \mathrm{~min}$ (range 3.5-20.2).

Acknowledging that the inputs can be varied, as outlined above, we offer examples illustrating the two scenarios described above. We assume an equal probability of changing categories over time, specific to each starting category, but that parameter can be modified as required to fit program-specific need data. In the first example, we start year 1 with zero patient volume and assume 1000 patients at the end of year 1, 3000 patients at the end of year 2, and 7000 patients at the end of year 3 (ramp-up scenario). Full staffing requirements, from the system perspective, are summarized in Table 1 . In summary, 4.8 nurse FTE would be required in year 1 , 13.5 nurse FTE in year 2, and 30.2 nurse FTE in year 3.

In the second example, we start year 1 with zero patient volume and assume a constant monthly enrollment of 100 patients (steady-state scenario). Full staffing requirements, from the system perspective, are summarized in Table 2. In summary, 5.8 nurse FTE would be required in year 1, 10.5 nurse FTE in year 2, and 14.3 nurse FTE in year 3. Other staff categories for each time period are provided in Table 2.

\section{Discussion}

We present here a workforce estimation model for hypertension management that takes into account patient need and health system capacity, resulting in full-time equivalent health worker staffing estimates for hypertension management in rural western Kenya. We used a triangulation approach, combining data from key informant interviews, focus group discussions, a Delphi exercise, timemotion studies, and clinical management protocols, in order to generate inputs for the need and capacity parameters of the workforce estimation model. Based on the AMPATH hypertension treatment protocols, we were able to categorize patients according to clinical state, frequency of clinical encounters, and outcome from each encounter. The Excel-based model allowed for either ramp-up (increasing number of patients per year) or steady-state (constant enrollment per month) scenarios, thus yielding FTE requirements for nurses and other cadres of health worker at each yearly time point.

Our model allows for key inputs to be varied. For need, the model can accommodate variations in the number of patients, proportion of patients within each category, percentage of patients who change categories over time, and required number of clinical encounters per month. With respect to the capacity, the model can be modified according to the number of days per month when hypertension patients are seen in the health facility, number of hours available per health worker for clinical encounters, and amount of time spent per clinical encounter. While we presented two illustrative scenarios, the various inputs can be modified as required in order to be specific to each setting and program. A live Excel workbook is provided as an Additional file 1 for those interested to work directly with the model.

Our approach for generating the need and capacity inputs consisted of combining results from distinct participant groups and data sources, using a combination of qualitative methods, a Delphi exercise, quantitative timemotion studies, and categorization of established clinical protocols. This approach allowed for triangulation across participant characteristics, study procedures, deductive and inductive content coding, and analytic approaches. Triangulation is a process of comparing the results from multiple distinct analytic approaches or sources of data, in order to enhance construct validity and trustworthiness of inferences [24, 25]. While there were substantial consistency and congruence of our results, there were also some notable variation. These differences reveal the

Table 1 Workforce requirements at years 1, 2, and 3, according to the ramp-up scenario

\begin{tabular}{|l|l|l|l|l|l|l|l|l|l|}
\hline & \multicolumn{3}{|l|}{ Staff Capacity } & \multicolumn{2}{l|}{ End Year 1 } & \multicolumn{2}{l|}{ End Year 2 } & \multicolumn{2}{l|}{ End Year 3 } \\
\hline Staff Member & $\begin{array}{l}\text { Visits } \\
\text { /day per } \\
1 \text { FTE }\end{array}$ & $\begin{array}{l}\text { Visits } \\
\text { /year for } \\
1 \text { FTE }\end{array}$ & $\begin{array}{l}\text { Visits } \\
\text { /month }\end{array}$ & $\begin{array}{l}\text { Visits } \\
\text { /month } \\
\text { required }\end{array}$ & $\begin{array}{l}\text { FTE } \\
\text { required }\end{array}$ & $\begin{array}{l}\text { Visits } \\
\text { /month } \\
\text { required }\end{array}$ & $\begin{array}{l}\text { FTE } \\
\text { required }\end{array}$ & $\begin{array}{l}\text { Visits } \\
\text { /month } \\
\text { required }\end{array}$ & $\begin{array}{l}\text { FTE } \\
\text { required }\end{array}$ \\
\hline Physician & 10 & 240 & 20 & 96 & 4.8 & 259 & 13.0 & 551 & 27.6 \\
\hline Clinical Officer & 30 & 720 & 60 & 264 & 4.4 & 841 & 14.0 & 1991 & 33.2 \\
\hline Nurse & 40 & 971 & 81 & 388 & 4.8 & 1094 & 13.5 & 2444 & 30.2 \\
\hline Pharmacist & 50 & 1200 & 100 & 739 & 7.4 & 2162 & 21.6 & 4901 & 49.0 \\
\hline $\begin{array}{l}\text { Triage Staff } \\
\text { /Technician }\end{array}$ & 50 & 1200 & 100 & 747 & 7.5 & 2189 & 21.9 & 4974 & 49.7 \\
\hline \multicolumn{2}{|l|}{ Work days/year: } & 24 & - & - & - & - & - & - & - \\
\hline
\end{tabular}

Work days per year is based on an estimation that hypertension patients are seen on 2 days per month 
Table 2 Workforce requirements at years 1, 2, and 3, according to the steady-state scenario

\begin{tabular}{|l|l|l|l|l|l|l|l|l|l|}
\hline & \multicolumn{3}{|l|}{ Staff Capacity } & \multicolumn{2}{l|}{ End Year 1 } & \multicolumn{2}{l|}{ End Year 2 } & \multicolumn{2}{l|}{ End Year 3 } \\
\hline Staff Member & $\begin{array}{l}\text { Visits } \\
\text { /day per } \\
\text { 1 FTE }\end{array}$ & $\begin{array}{l}\text { Visits } \\
\text { /year for } \\
\text { 1 FTE }\end{array}$ & $\begin{array}{l}\text { Visits } \\
\text { /month }\end{array}$ & $\begin{array}{l}\text { Visits } \\
\text { /month } \\
\text { required }\end{array}$ & $\begin{array}{l}\text { FTE } \\
\text { required }\end{array}$ & $\begin{array}{l}\text { Visits } \\
\text { /month } \\
\text { required }\end{array}$ & $\begin{array}{l}\text { FTE } \\
\text { required }\end{array}$ & $\begin{array}{l}\text { Visits } \\
\text { /month } \\
\text { required }\end{array}$ & $\begin{array}{l}\text { FTE } \\
\text { required }\end{array}$ \\
\hline Physician & 10 & 240 & 20 & 116 & 5.8 & 195 & 9.8 & 235 & 11.7 \\
\hline Clinical Officer & 30 & 720 & 60 & 316 & 5.3 & 692 & 11.5 & 1064 & 17.7 \\
\hline Nurse & 40 & 971 & 81 & 466 & 5.8 & 847 & 10.5 & 1154 & 14.3 \\
\hline Pharmacist & 50 & 1200 & 100 & 887 & 8.9 & 1707 & 17.1 & 2399 & 24.0 \\
\hline $\begin{array}{l}\text { Triage Staff } \\
\text { /Technician }\end{array}$ & 50 & 1200 & 100 & 896 & 9.0 & 1731 & 17.3 & 2447 & 24.5 \\
\hline
\end{tabular}

Work days per year is based on an estimation that hypertension patients are seen on 2 days per month

diversity of stakeholder perspectives. Such differences also highlight the importance of being able to vary the inputs in the model, in order to generate ranges of estimates useful for program planning and policy formulation.

A key component of the workforce estimation model was the translation of the AMPATH hypertension clinical protocol into a discrete number of "clinician-frequency" combinations, each with a schedule of encounters, with re-assessment of status at 6-month intervals, as described in detail above. We elected to create six categories, with follow-up periods that ranged from 1 to 6 months depending on the clinical provider and with no variability in the re-assessment time interval. While this might not mimic clinical practice exactly, we felt it was a reasonable approximation while still yielding a model that was manageable and feasible to manipulate. Depending on the complexity of the clinical algorithm, the granularity with which the end-user wishes to categorize different patientclinician combinations, the frequency of re-assessments, and the likelihood of patients changing categories over time, this process can be modified.

Given the burden of hypertension and other noncommunicable diseases (NCDs) around the world, it is critical that governments, health systems, and health facilities account for NCD-related health workforce requirements in their planning and implementation processes [26]. The World Health Organization (WHO) Global Strategy for human resources for health states that the supply of health care workers needs to reflect the increasing burden of NCDs [27], and this type of health workforce estimation model can assist health facilities, programs, and governments with human resource planning. While we have limited our model and analysis to health workers within the formal health system, other cadres of health worker, such as community health workers, can also positively impact outcomes for hypertension and other NCDs $[28,29]$. Our model can be modified to take into account community health workers and other allied health professionals, as required.
One limitation of our approach is that, as with any model, the assumptions and inputs may not reflect exactly the reality on the ground. While we acknowledge that this is an issue, we feel that the model is flexible enough to accommodate variations in the inputs as required to match alternative scenarios. Second, we assumed that no patients were lost to follow-up or died. However, this parameter can be incorporated into the model as required, and workforce FTE estimations would be adjusted accordingly. Third, the needsbased approach proposed here assumes that hypertensionrelated health care should be provided according to need irrespective of other considerations. However, other factors may determine healthcare delivery, including costs, competing health priorities, cultural considerations, and societal values. Finally, we acknowledge that other models of health workforce estimation are available, such as task-based, demand-based, health-workforce-to-population ratio, service target-based, and probabilistic supply-demand matching, and each has its respective benefits and drawbacks [30-32]. Nevertheless, the current proposal is a critical first step in establishing a benchmark for health workforce estimation for hypertension management in LMICs.

\section{Conclusions}

A needs-based workforce estimation model yielded fulltime equivalent estimates for different health worker cadres required for hypertension management in western Kenya. The model is able to provide workforce projections that are useful for program planning, human resource allocation, and policy formulation. This approach can serve as a benchmark for future studies to manage chronic diseases in low-resource settings worldwide.

\section{Additional file}

Additional file 1: Draft Excel model 20160508 BACKUP. (XLSX 677 kb)

\section{Abbreviations}

AMPATH: The Academic Model Providing Access to Healthcare Partnership; BP: Blood pressure; CDM: Chronic disease management; DBP: Systolic blood 
pressure; FGD: Focus group discussions; FTE: Full-time equivalents; HIV: Human immunodeficiency virus; JNC 7: Seventh Report of the JNC; JNC 8: Eight Report of the JNC; JNC: Joint National Committee on Prevention, Detection, Evaluation, and Treatment of High Blood Pressure; KIl: Key informant interviews; LMIC: Low- and middle-income countries; NCDs: Noncommunicable diseases; SBP: Systolic blood pressure; WHO: The World Health Organization

\section{Acknowledgements}

The authors would like to thank the AMPATH Chronic Disease Management Program staff and clinicians for their assistance with all aspects of the project. We would also like to thank all research participants, as well as the Delphi exercise participants.

\section{Authors' contributions}

RV and DL made substantial contributions to the conception and design of the work.

$\mathrm{RV}$ and $\mathrm{DL}$ contributed to the acquisition of data. RV, DL, JK, OH, PK DT, $\mathrm{SK}, \mathrm{HB}$, and VF contributed to the analysis of the data and the interpretation of the results. $\mathrm{RV}, \mathrm{DL}$, and $\mathrm{OH}$ were major contributors in writing and/or substantially revising the manuscript. All authors read and approved the final manuscript.

\section{Funding}

Research reported in this publication was supported by the Fogarty International Center of the National Institutes of Health under award number K01 TW 009218 05. The content is solely the responsibility of the authors and does not necessarily represent the official views of the National Institutes of Health.

\section{Availability of data and materials}

This study complies with the NIH Public Access Policy, which ensures that the public has access to the published results of $\mathrm{NIH}$-funded research, and therefore, all results have been (and will be made) available from final peerreviewed journal manuscripts (including this one) via the digital archive PubMed Central upon acceptance for publication. The data can be made available to other investigators upon formal request made to the Academic Model Providing Access to Healthcare (AMPATH) Research Manager.

\section{Ethics approval and consent to participate}

This study obtained ethics approval by the Mount Sinai School of Medicine International Review Board (IRB) in New York, NY (HS\#:11-01808), as well as the Moi University School of Medicine Institutional Research and Ethics Committee (IREC) in Eldoret, Kenya (IREC Approval Number 000744).

\section{Consent for publication}

Not applicable

\section{Competing interests}

The authors declare that they have no competing interests.

\section{Author details}

${ }^{1}$ New York University School of Medicine, 180 Madison Avenue, 8th Floor, New York, NY 10016, USA. ${ }^{2}$ Temple University School of Medicine, $3500 \mathrm{~N}$ Broad St, Philadelphia, PA 19140, USA. ${ }^{3}$ Department of Medicine, School of Medicine, Moi University College of Health Sciences, Nandi Rd, Eldoret, Kenya. ${ }^{4}$ Weill Cornell Medicine, 413 East 69th Street, New York, NY 10021, USA. ${ }^{5}$ Academic Model Providing Access to Healthcare (AMPATH), P.O. Box 4606, Eldoret 30100, Kenya. 'University of Massachusetts, 306 Godell, Amherst, MA 01003, USA. ${ }^{7}$ Icahn School of Medicine at Weill Cornell, 1 Gustave L. Levy PI, New York, NY 10029, USA.

Received: 6 March 2019 Accepted: 20 June 2019

Published online: 16 July 2019

\section{References}

1. Gakidou E, Afshin A, Abajobir AA, Abate KH, Abbafati C, Abbas KM, et al. Global, regional, and national comparative risk assessment of 84 behavioural, environmental and occupational, and metabolic risks or clusters of risks, 1990-2016: a systematic analysis for the Global Burden of Disease Study 2016. The Lancet. 390(10100):1345-1422.
2. Chow CK, Teo KK, Rangarajan S, Islam S, Gupta R, Avezum A, et al. Prevalence, awareness, treatment, and control of hypertension in rural and urban communities in high-, middle-, and low-income countries. JAMA: the journal of the American Medical Association. 2013;310(9):959-68.

3. Mills KT, Bundy JD, Kelly TN, Reed JE, Kearney PM, Reynolds K, et al. Global disparities of hypertension prevalence and control: a systematic analysis of population-based studies from 90 countries. Circulation. 2016;134(6):441-50.

4. Cutler JA, Sorlie PD, Wolz M, Thom T, Fields LE, Roccella EJ. Trends in hypertension prevalence, awareness, treatment, and control rates in United States adults between 1988-1994 and 1999-2004. Hypertension. 2008;52(5): 818-27.

5. Egan BM, Zhao Y, Axon RN. US trends in prevalence, awareness, treatment, and control of hypertension, 1988-2008. JAMA : the Journal of the American Medical Association. 2010;303(20):2043-50.

6. Nelson SA, Dresser GK, Vandervoort MK, Wong CJ, Feagan BG, Mahon JL, et al. Barriers to Blood Pressure Control: A STITCH Substudy. J Clin Hypertens (Greenwich). 2011;13(2):73-80.

7. Morgado M, Rolo S, Macedo AF, Pereira L, Castelo-Branco M. Predictors of uncontrolled hypertension and antihypertensive medication nonadherence. J Cardiovasc Dis Res. 2010;1(4):196-202.

8. Seedat YK. Impact of poverty on hypertension and cardiovascular disease in sub-Saharan Africa. Cardiovasc J Afr. 2007;18(5):316-20.

9. Wang PS, Bohn RL, Knight E, Glynn RJ, Mogun H, Avorn J. Noncompliance with antihypertensive medications: the impact of depressive symptoms and psychosocial factors. J Gen Intern Med. 2002;17(7):504-11.

10. Vedanthan R, Fuster V. Urgent need for human resources to promote global cardiovascular health. Nat Rev Cardiol. 2011;8:114-7.

11. Joshi R, Alim M, Kengne AP, Jan S, Maulik PK, Peiris D, et al. Task Shifting for Non-Communicable Disease Management in Low and Middle Income Countries - A Systematic Review. PLOS ONE. 2014;9(8):e103754.

12. Ogedegbe G, Plange-Rhule J, Gyamfi J, Chaplin W, Ntim M, Apusiga K, et al. Health insurance coverage with or without a nurse-led task shifting strategy for hypertension control: A pragmatic cluster randomized trial in Ghana. PLoS Med. 2018;15(5):e1002561.

13. Hagopian A, Micek MA, Vio F, Gimbel-Sherr K, Montoya P. What if we decided to take care of everyone who needed treatment? Workforce planning in Mozambique using simulation of demand for HIV/AIDS care. Human resources for health. 2008:6:3.

14. Einterz RM, Kimaiyo S, Mengech HN, Khwa-Otsyula BO, Esamai F, Quigley F, et al. Responding to the HIV pandemic: the power of an academic medical partnership. Acad Med. 2007;82(8):812-8.

15. Bloomfield GS, Kimaiyo S, Carter EJ, Binanay C, Corey GR, Einterz RM, et al. Chronic noncommunicable cardiovascular and pulmonary disease in subSaharan Africa: an academic model for countering the epidemic. Am Heart J. 2011;161(5):842-7.

16. Vedanthan R, Kamano JH, Bloomfield GS, Manji I, Pastakia S, Kimaiyo SN Engaging the entire care cascade in western kenya: a model to achieve the cardiovascular disease secondary prevention roadmap goals. Global heart. 2015;10(4):313-7.

17. Neuendorf KA. The Content Analysis Guidebook. Thousand Oaks: Sage Publications; 2002.

18. Vedanthan R, Kamano JH, Naanyu V, Delong AK, Were MC, Finkelstein EA, et al. Optimizing linkage and retention to hypertension care in rural kenya: rationale and design of the LARK hypertension study. Trials. 2014;15:143.

19. Hasson F, Keeney S, McKenna H. Research guidelines for the Delphi survey technique. Journal of advanced nursing. 2000;32(4):1008-15.

20. James PA, Oparil S, Carter BL, Cushman WC, Dennison-Himmelfarb C, Handler J, et al. 2014 evidence-based guideline for the management of high blood pressure in adults: report from the panel members appointed to the Eighth Joint National Committee (JNC 8). JAMA : the Journal of the American Medical Association. 2014;311(5):507-20.

21. Chobanian AV, Bakris GL, Black HR, Cushman WC, Green LA, Izzo JL Jr, et al. The Seventh Report of the Joint National Committee on Prevention, Detection, Evaluation, and Treatment of High Blood Pressure: the JNC 7 report. JAMA : the Journal of the American Medical Association. 2003; 289(19):2560-72.

22. Management C, Guidelines R, Volume III. Nairobi. Kenya: Ministry of Medical Services and Ministry of Public Health and Sanitation; 2010.

23. Kumar A, Kamano JH, Too K, Tulienge D, Wambui C, Okidi E, et al. Effect of nurse-based management of hypertension in rural western Kenya. American College of Cardiology Scientific Sessions; Chicago, USA2016. 
24. Jick TD. Mixing qualitative and quantitative methods: triangulation in action Administrative Science Quarterly. 1979;24(4):602-11.

25. Rothbauer PM. Triangulation. The SAGE Encyclopedia of Qualitative Research Methods. SAGE Publications, Inc. Thousand Oaks: SAGE Publications, Inc. p. 893-5.

26. Olsen MH, Angell SY, Asma S, Boutouyrie P, Burger D, Chirinos JA, et al. A call to action and a lifecourse strategy to address the global burden of raised blood pressure on current and future generations: the Lancet Commission on hypertension. The Lancet. 2016;388(10060):2665-712.

27. Global strategy on human resources for health, workforce 2030. Geneva: World Health Organization. p. 2016.

28. Abdel-All M, Putica B, Praveen D, Abimbola S, Joshi R. Effectiveness of community health worker training programmes for cardiovascular disease management in low-income and middle-income countries: a systematic review. BMJ open. 2017;7(11):e015529.

29. Alaofe H, Asaolu I, Ehiri J, Moretz H, Asuzu C, Balogun M, et al. Community Health Workers in Diabetes Prevention and Management in Developing Countries. Ann Glob Health. 2017;83(3-4):661-75.

30. Dreesch N, Dolea C, Dal Poz MR, Goubarev A, Adams O, Aregawi M, et al. An approach to estimating human resource requirements to achieve the Millennium Development Goals. Health Policy Plan. 2005;20(5):267-76.

31. Bärnighausen T, Bloom DE. The global health workforce. In: Smith P, Glied S, editors. Oxford Handbook of Health Economics. Oxford: Oxford University Press. In press.

32. Hirschhorn LR, Oguda L, Fullem A, Dreesch N, Wilson P. Estimating health workforce needs for antiretroviral therapy in resource-limited settings. Human resources for health. 2006;4:1.

\section{Publisher's Note}

Springer Nature remains neutral with regard to jurisdictional claims in published maps and institutional affiliations.

Ready to submit your research? Choose BMC and benefit from:

- fast, convenient online submission

- thorough peer review by experienced researchers in your field

- rapid publication on acceptance

- support for research data, including large and complex data types

- gold Open Access which fosters wider collaboration and increased citations

- maximum visibility for your research: over $100 \mathrm{M}$ website views per year

At $\mathrm{BMC}$, research is always in progress.

Learn more biomedcentral.com/submissions 